\title{
Physician Preferences for Botulinum Toxin Injections in Anticoagulated Patients with Spasticity
}

\author{
Adam Kassam, Chetan P. Phadke, Farooq Ismail, Chris Boulias
}

\begin{abstract}
To understand physician preferences and bleeding complication rates of intramuscular botulinum neurotoxin type A injections for spasticity management in anticoagulated patients, questionnaires were mailed to 138 physicians across Canada. The international normalized ratio comfort range for injections was <2.0 in 10\%, 2.0 to 2.5 in $35 \%, 2.6$ to 3.0 in $25 \%$, and 3.1 to 3.5 in $20 \%$ of physicians. Only $23 \%$ injected outside their comfort value and $57 \%$ did not; $72 \%$ did not normalize the international normalized ratio value before injections. Only one injector reported the development of compartment syndrome. As expected, high variability exists in physician preferences in botulinum neurotoxin type A injection in anticoagulated patients.
\end{abstract}

RÉSUMÉ: Préférences des médecins en ce qui a trait aux injections de toxine botulinique données à des patients atteints de spasticité et recevant un traitement anticoagulant. Pour connaître les préférences des médecins ainsi que le taux de complications hémorragiques en ce qui a trait aux injections intramusculaires de toxine botulinique de type A données à des patients traités pour la spasticité et recevant un traitement anticoagulant, des questionnaires ont été envoyés à 138 médecins aux quatre coins du Canada. Les seuils d'acceptabilité de taux de prothrombine (TP) étaient $<2,0$ pour $10 \%$ des médecins; 2,0 à 2,5 pour $35 \%$ d'entre eux; 2,6 à 3,0 pour $25 \%$ d'entre eux; et finalement 3,1 à 3,5 pour $20 \%$ d'entre eux. Seulement $23 \%$ des médecins ont procédé à des injections au-delà de leur seuil d'acceptabilité tandis que 57\% d'entre eux s'y sont refusés. Enfin, $72 \%$ des médecins n'ont pas normalisé le seuil d'acceptabilité de TP avant de procéder à des injections. Fait à noter, seul un médecin a signalé l'apparition d'un syndrome des loges. Comme on pouvait s'y attendre, il existe chez les médecins une forte variabilité de préférences en ce qui regarde l'injection de toxine botulinique de type A chez des patients recevant un traitement anticoagulant.

Keywords: botulinum toxin, anticoagulants, stroke, hemorrhage, compartment syndromes, physicians, health surveys

doi:10.1017/cjn.2015.397

Can J Neurol Sci. 2016; 43: 581-583

Factors that alter risk of bleeding are particularly relevant in patients being treated with botulinum neurotoxin type A (BoNTA) injections because multiple intramuscular injections can increase the potential for hematoma formation, and, more seriously, in the case where deep compartmentalized muscles are targeted, compartment syndrome. A hematoma is defined as a localized swelling filled with blood caused by a break in a wall of a vessel. If enough blood accumulates, pressure within deep compartments of the affected limb can rise substantially and result in a compartment syndrome, a clinical emergency characterized by pain, paresthesia, pulselessness, and ischemia. If left untreated, compartment syndrome can result in permanent muscle and nerve damage and or limb loss.

Bleeding during needle electromyelography (EMG) procedures has been reported in up to $29 \%$ non-anticoagulated patients ${ }^{1}$ and even lower $(1 \%)$ in patients on anticoagulants. ${ }^{2}$ BoNTA injection technique is very similar to the technique used during intramuscular needle EMG procedures. One major difference is that BoNTA is usually administered in multiple injection sites, which may confer additional bleeding and hematoma risks compared with needle EMG. Bleeding complications from BoNTA injections have been reported for indications such as detrusor hyperactivity, ${ }^{3}$ dystonia, blepharospasm, ${ }^{4}$ hemifacial spasm, ${ }^{4}$ and spasticity in anticoagulated patients. ${ }^{5}$ No minor or major bleeding was reported after BoNTA injections for spasticity in anticoagulated patients. ${ }^{4,5}$ Thus, results from these studies demonstrate low rates of bleeding following intramuscular BoNTA injections.

In previous studies in patients who were on anticoagulants and experienced bleeding post-BoNTA injection, the international normalized ratio (INR) ranged from 1.7 to 3.5 . With such a wide range of INRs associated with bleeding and in the absence of guidelines specific to BoNTA injections, ${ }^{6}$ a diverse range of approaches relating to injecting patients on anticoagulant therapy exists. This makes it difficult to formulate an understanding of the overall standard of practice among physicians. Therefore, the purpose of this study was to better understand individual

From the Spasticity Research Program (AK, CPP, FI, CB), West Park Healthcare Centre, Toronto, ON, Canada; Department of Physical Medicine \& Rehabilitation (AK), Schulich School of Medicine \& Dentistry, Western University, London, ON, Canada; Department of Physical Therapy (CPP), University of Toronto, ON, Canada; Faculty of Health (CPP), York University, Toronto, ON, Canada; Division of Physiatry, Department of Medicine (FI, CB), University of Toronto, Toronto, ON, Canada.

Received May 6, 2015. Final Revisions Submitted November 25, 2015. Correspondence to: Chris Boulias, Spasticity Research Program, West Park Healthcare Centre, Toronto, ON M6M 2J5.

Email: Chris.Boulias@westpark.org 


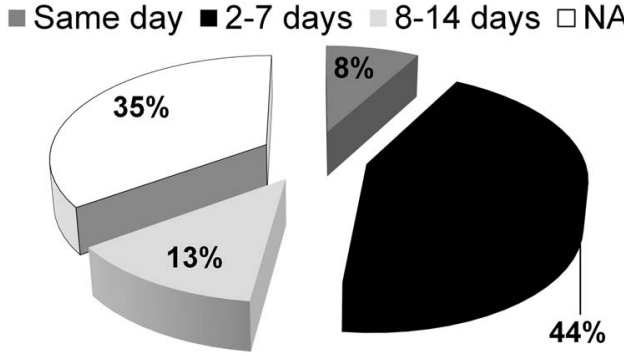

Figure 1: Time of INR measurement before BoNTA injection

preferences, techniques used, and the prevalence of BoNTA injection-related bleeding complications among Canadian physicians using BoNTA for spasticity management in patients on anticoagulant therapy.

\section{METHODS}

This prospective cross-sectional study was approved by the Joint Research Ethics Board. A total of 138 physicians were mailed a questionnaire (Appendix 1) created by the investigators of this study and a cover letter outlining implied consent with completion of the survey and study goals. Two reminder messages were then mailed to participants 10 and 20 days later. Data collected from the survey responses were analyzed using SPSS, version 20 (IBM Corporation, Armonk, NY).

\section{Results}

\section{Quantitative Data}

Seventy physicians completed the survey, which represents a response rate of $51 \%$. Forty percent of physicians who responded were from Ontario, with smaller percentages from Quebec (19\%), British Columbia (13\%), Alberta (10\%), Manitoba (6\%), Nova Scotia (4\%), and less than $3 \%$ from rest of the provinces. The majority of physicians surveyed $(88 \%)$ had at least 3 years of experience with BoNTA injections, with $77 \%$ having greater than 5 years' experience. Additionally, $65 \%$ of respondents injected at least 10 patients monthly, with $25 \%$ injecting more than 30 patients per month. Responders included physiatrists $(67 \%)$, neurologists (29\%), and other specialties (4\%: anesthesiology, family medicine, and dermatology).

Forty-four percent of physicians reported that approximately half of their patients receiving BoNTA were on warfarin. Forty-four percent of the physicians were aware of the INR value of their patients on the day of the injection, whereas $44 \%$ were unaware. Of those who were unaware of the same-day INR values, 53\% still injected BoNTA. Broadly, $21 \%$ of physicians reported injecting regardless of INR values, with only $44 \%$ of providers having the ability to measure the INR on the same day. Fifty-nine percent of the INR values were obtained by sending blood to the laboratory, with $45 \%$ of providers using INR values between 2 and 7 days before injection (Figure 1).

Physicians were also surveyed regarding their comfort INR ranges for injections (Figure 2). The INR comfort range for injections was less than 2.0 in $7 \%$ of physicians, between 2.0 and 2.5 in $34 \%$, between 2.6 and 3.0 in $24 \%$, and between 3.1 and 3.5 in $16 \%$ of physicians. Only $23 \%$ injected outside their comfort

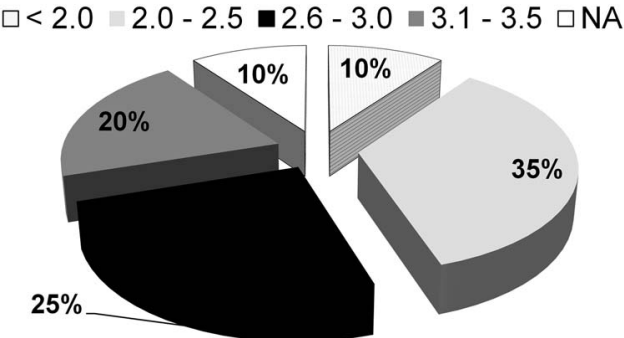

Figure 2: Comfort INR range for BoNTA injection

value, whereas $71 \%$ did not normalize INR values before injections. Several questions had the option for the physician to decline a response; hence, a few of the responses do not add up to $100 \%$. Overall, $83 \%$ of physicians injected muscles of the deep compartments, and only $1 \%$ of physicians surveyed reported the development of compartment syndrome after a deep compartment intramuscular injection.

\section{Qualitative Data}

One physician reported compartment syndrome with one large hematoma in the arm after injection in a patient with a very high INR (the actual value was not reported). Although the muscle injected was not reported in the survey, this physician reported using a combination of electrical stimulation, EMG, and ultrasound guidance for BoNTA injections. This event resulted in a change of practice for this physician, in which INR within a week before injection was checked and if in doubt checked again using point-of-care INR values. Ever since this practice was adopted, no other cases of hematoma formation or compartment syndrome were reported in this physician's practice. A second physician reported bleeding in the psoas muscle after EMG-guided BoNTA injection, resulting in acute renal failure. This patient had received successful BoNTA injections in the past without warfarin reversal; however, bleeding resulted in spite of past success and use of computed tomography-guided injections. The patient survived, but it was a traumatic experience. Consequently, this physician never again injected without reversal of warfarin when injecting deep muscles such as psoas, where application of pressure is difficult.

\section{DISCUSSION}

Thrombosis Canada has made recommendations on perioperative management of patients receiving warfarin and risk stratification based on procedures. However, these guidelines do not mention BoNTA injections or needle EMG as part of their procedural risk stratification. ${ }^{6}$ Nevertheless, in the absence of guidelines specific to BoNTA injections, a wide range of approaches relating to injecting patients on anticoagulant therapy exists. ${ }^{6}$

Based on our data, physicians tended to be conservative with monitoring INR values before BoNTA injections. Unfortunately, less than half of injectors have access to same-day INR levels, with roughly the same percentage of physicians relying on INR values between 2 and 7 days before the injections. The majority of physicians endorsed a comfort with injecting below an INR value of 3, with most preferring to inject between INR values 2 and 3 .

Considering the number of years of experience injecting as well as the volume of patients, the rate of compartment syndrome 
following BoNTA injections in anticoagulated patients in this study $(n=1)$ is extremely low. Although we did not ask respondents the needle size used, the standard needle size for intramuscular injections for upper and lower limb spasticity is between 25 and 30 gauge, ${ }^{7}$ and a previous report using a 27 -gauge needle did not report any cases of hematoma or compartment syndrome in anticoagulated as well as control groups. ${ }^{4}$ However, a case report of compartment syndrome ${ }^{8}$ after needle EMG using a 30-gauge needle recommended caution using needle EMG in anticoagulated patients.

Neither hematoma formation nor compartment syndrome is common after needle EMG. In fact, even after performing needle EMG in hundreds of at-risk muscles including deep compartment muscles in the arm and leg, only two cases of subclinical hematoma formation assessed using ultrasound were seen. ${ }^{9}$ In spite of such a low occurrence of hematomas, a recent case report of compartment syndrome as a result of needle EMG examination prescribed caution using needle EMG in anticoagulated patients. ${ }^{8}$ This case report and personal experience of physicians combined with a lack of guidelines pertinent to BoNTA injections can help explain the conservative practice and reluctance of physicians in this study to inject without checking INR.

The pharmacotherapy management of anticoagulation is currently changing. Warfarin has long been the drug of choice; however, new oral anticoagulants are being introduced in clinical practice. Two of the new major drug categories, direct thrombin inhibitors and direct factor Xa inhibitors, do not require INR monitoring. ${ }^{10}$ Specifically, as the new drug's use becomes more prevalent, INR monitoring before BoNTA injections may become an obsolete practice. The bleeding risk will need to be explored in the future as the injectors gain more experience with injections in patients on the new anticoagulants.

\section{Limitations}

A relatively low number of physicians were surveyed. The impact of the use of new direct oral anticoagulants was not examined in this study.

\section{Conclusions}

There is great heterogeneity in terms of physician preference and comfort when treating anticoagulated spasticity patients with BoNTA injections. This heterogeneity is likely from an absence of formalized guidelines on how to approach anticoagulated patients with BoNTA injections. The risk of bleeding and compartment syndrome following BoNTA injections in anticoagulated patients is very low and likely of low clinical concern. The rising use of new direct oral anticoagulants will ultimately change the practice of surveillance before BoNTA injections, and new guidelines taking this into account will be essential for standardizing physician practice.

\section{Disclosures}

AK has nothing to disclose. $\mathrm{CP}$ has received a grant unrelated to the current study and a grant to his institution from Allergan
Inc./Merz and has grants or grants pending from the Ontario Federation for Cerebral Palsy (OFCP; to institution); travel/ accommodations/meeting expenses unrelated to activities listed from the West Park Foundation; and Department of Physical Therapy, University of Toronto, lectures. FI has received a grant (to institution) and support for travel to meetings for the study or other purposes (to institution) from Allergan (money to institution); and is a board member for Allergan and Merz; has grants or grants pending from OFCP (to institution); payment for lectures including service on speakers bureaus for Allergan and Merz; payment from Allergan for development of educational presentations; and travel/accommodations/meeting expenses unrelated to activities listed from Allergan and Merz. CB has received a grant (to institution) from Allergan Inc/Merz; support for travel to meetings for the study or other purposes (to institution) from Allergan Inc; and has grants or grants pending from OFCP; has consulted for Allergan and Merz; received payment for lectures including service on speakers bureaus from Allergan and Merz; received payment for development of educational presentations from Allergan; and received travel/accommodations/meeting expenses unrelated to activities listed from Allergan and Merz.

\section{SUPPLEMENTARY MATERIAL}

To view supplementary material for this article, please visit http://dx.doi.org/10.1017/cjn.2015.397

\section{REFERENCES}

1. Caress JB, Rutkove SB, Carlin M, Khoshbin S, Preston DC. Paraspinal muscle hematoma after electromyography. Neurology. 1996;47:269-72.

2. Lynch SL, Boon AJ, Smith J, Harper CM, Tanaka EM. Complications of needle electromyography: hematoma risk and correlation with anticoagulation and antiplatelet therapy. Muscle Nerve. 2008;38: 1225-30.

3. Akkoc Y, Kirazli Y, Ozdedeli S, Ozyurt C. Complication of botulinum-A toxin treatment of neurogenic detrusor overactivity in a patient taking oral anticoagulation therapy: massive hematuria. J Rheumatol Rehabil Med. 2006;17:291-4.

4. Schrader C, Tacik P, Ebke M, Dressler D. Botulinum toxin therapy in patients with oral anticoagulation: hematoma frequency vs. other side effects. Movement Disorders. 2012;27.

5. Jagatsinh Y, George J. Audit of safety of intramuscular botulinum toxin injections among patients receiving warfarin anticoagulation therapy. IJPMR. 2012;23.

6. Thrombosis Canada. Warfarin perioperative management. http:// www.thrombosiscanada.ca/guides/pdfs/Warfarin_perioperative_ management.pdf.

7. Alter KE, Hallett M, Karp B, Lungu C. Ultrasound-guided chemodenervation procedures: text and atlas. New York: Demos Medical Publishing; 2012.

8. Brown SM, Williams TL, Whittaker RG. A cautionary tale: threatened compartment syndrome following electromyography in an anticoagulated patient. Muscle Nerve. 2012;46:144-6.

9. Boon AJ, Gertken JT, Watson JC, et al. Hematoma risk after needle electromyography. Muscle Nerve. 2012;45:9-12.

10. Connolly SJ, Ezekowitz MD, Yusuf S, et al. Dabigatran versus warfarin in patients with atrial fibrillation. $\mathrm{N}$ Engl $\mathrm{J}$ Med. 2009;361:1139-51 